\title{
Effect of the Mycelial Culture of Ganoderma lucidum on Human Pathogenic Bacteria
}

\author{
Ofodile Lauretta Nwanneka (Corresponding author) \\ Department of Biological Science, Yaba College of Technology \\ P. M. B. 2011, Yaba, Lagos, Nigeria
}

Tel: 234-803-300-4212 E-mail: nwannemka@yahoo.com

$$
\text { A.O. Ogbe }
$$

1Federal College of Animal Health and Production Technology, National Veterinary Research Institute, Vom, Nigeria

Oladipupo Olufunke

Department of Biological Science, Yaba College of Technology

P. M. B. 2011, Yaba, Lagos, Nigeria

Tel: 234-702-922-1041Ｅ-mail: funkeoladipupo@yahoo.com

Received: July 15, 2010 Accepted: July 30, 2010 doi:10.5539/ijb.v3n2p111

\begin{abstract}
The mycelial culture of Ganoderma lucidum found in Nigeria was tested on some human pathogenic bacteria using dual and Weller techniques. The mycelial culture was active against all the test organisms: Escherichia coli, Staphylococcus aureus, Klebsiella pneumoniae and Pseudomonas aeruginosa. The bacterium, Escherichia coli showed the highest susceptibility to the mushroom mycelia at $10.6 \mathrm{~mm}$ on the first day of incubation which increased to $15.2 \mathrm{~mm}$ on the fourth day using the dual method while Pseudomonas aeruginosa showed the least susceptibility of $5.7 \mathrm{~mm}$ on the fourth day. In the Weller method the growth of the test organisms were completely antagonized by the mycelia of Ganoderma lucidum as total inhibition was recorded from all the plates. These could be an indication that Ganoderma lucidum can be used in the treatment of diseases caused by these organisms as well as preventive measure against them.
\end{abstract}

Keywords: Bacteria, Ganoderma lucidum, Mycelial culture, Prevention, Preatment

\section{Introduction}

Ganoderma lucidum known as lingzhi in Chinese, reishi in Japanese, yeonghi in Korea is a mushroom in the group commonly known as polypores in the family Ganodermataceae and they have a worldwide distribution in both tropical and temperate region. (Ofodile, 2005). The genus Ganoderma fruit bodies are sessile or stipitate, with shinny upper surface having district context. They may be yellow, black, white and reddish to purple (Ofodile \& Bikomo, 2008).

Ganoderma species, especially Ganoderma lucidum is highly ranked medicinal mushroom in oriental traditional medicine which has been widely used for the therapy of chronic diseases of various etiologies. (Carmen \& Xin 2004). Ganoderma lucidum extract has been reported active against Bacillus subtilis and Pseudomonas syringes which are plant pathogen (Ofodile et al., 2005). Also the antimicrobial activity of Ganoderma lucidum extract from Nigeria has been reported by (Ofodile et al., 2005; Ofodile and Bikomo, 2008). Escherichia coli is known to cause gastro-enteritis, Staphylococcus aureus also causes food poisoning, vomiting and loss of fluid, Klebsiella pneumoniae causes lung abscess, bacteremia and Pseudomonas aeruginosa causes lung infection, urinary tract infection and septicemia. (Geo et al., 2005; Willey et al., 2008).

Mycelial culture of Ganoderma lucidum is the primary stage in the cultivation of the mushroom and its effect against human pathogen seems not to have been reported in Nigeria. This communication reports the effect of mycelial culture of Ganoderma lucidum as bioactive agent against Escherichia coli Staphylococcus aureus, Klebsiella Pneumoniae and Pseudomonas aeruginosa.

\section{Materials and methods}




\subsection{Mushroom sample}

Ganoderma lucidum sample was collected from National Research Institute Vom, Plateau State Nigeria. The mushroom was identified by its ornamental truncate spores which are oblong with one tapering end and other characteristics. (Zoberi, 1978; Smith \& Sivasthamparan, 2003; Ofodile, 2006).

\subsection{Bacteria used in the assay}

The test organisms E. coli, Staphylococcus aureus, Klebsiella pneumoniae and pseudomonas aeruginosa used in this study were obtained from microbiology laboratory, Lagos university teaching hospital, Idi-Araba Lagos. Each of the bacterium was maintained in sterile nutrient agar slant at $4^{\circ} \mathrm{C}$.

\subsection{Preparation of mushroom sample}

Mycelial culture of Ganoderma lucidum was obtained by rinsing the Ganoderma lucidum sample collected with sterile water for 2-3 minutes, sterilized by wiping with $70 \%$ alcohol under aseptic condition and then rinsed with water again. With the aid of sterile scapel, the basidiocarp of the mushroom sample was cut to expose the interior tissues, pieces of the tissue were excised and placed on PDA plates already prepared and plates were then incubated at $25^{\circ} \mathrm{C}$ for 5 days. From the developing mycelia, mycelial tissues were transferred using inoculating needle to fresh PDA plates and into slant tubes and stored in the refrigerator at $4^{\circ} \mathrm{C}$.

\subsection{The bioassay}

\subsubsection{Inoculation of the bacteria isolates with Ganoderma lucidum using dual method}

In this method the mycelia culture of Ganoderma lucidum was evaluated for its ability to grow and lyse the colonies of the bacteria species (Utkheda \& Rahe, 1980).

Fresh PDA plates were prepared and kept in a lamina flow in order to maintain sterility. Using a sterile cork borer of $6 \mathrm{~mm}$ diameter, two wells were made at opposite edge of the fresh PDA plates, using another sterile cork borer a disk culture of 7days old culture of Ganoderma lucidum was taken and placed into one of the wells previously made on the fresh PDA plate. Another sterile cork borer of $6 \mathrm{~mm}$ diameter was used to take a disk culture of $24 \mathrm{hrs}$ old culture of bacteria isolate which has been adjusted to a concentration of $10^{6}$ and inoculated it into the other well at the opposite edge of the plate already inoculated with Ganoderma lucidum culture. Each of the bacteria isolate and antagonist were placed at the opposite sides on the same plate at the same time (Utkhede $\&$ Rahe, 1980). This was done in triplicate for all the bacteria isolates and all the plates were incubated at $25^{\circ} \mathrm{C}$ and checked daily to measure the zone of inhibition for four consecutive days.

\subsubsection{Interaction between the bacteria species and the mycelial culture of Ganoderma lucidum}

Mycelial culture of the mushroom was tested against the four bacteria species on agar media using the method of Weller et al. (1985). In this method Ganoderma lucidum was evaluated for its ability to grow and lyse the colonies of bacteria. Fresh PDA medium was prepared, sterilized and poured into sterile plates. On each of the freshly prepared PDA plates two wells were made opposite to each other using $6 \mathrm{~mm}$ diameter cork borer. A culture disk of 7days old Ganoderma lucidum was placed in one of the well made on the plate using sterile cork borer. The plates were then incubated at $25^{\circ} \mathrm{C}$ for $48 \mathrm{hrs}$. After $48 \mathrm{hrs}$ of incubation a culture disk of $24 \mathrm{hrs}$ old culture of the bacteria isolates which have been adjusted to a concentration of $10^{6}$ was taken and placed in the other well in the plate already inoculated with mycelia of Ganoderma lucidum for $48 \mathrm{hrs}$ plates were then incubated at $25^{\circ} \mathrm{C}$ and were checked to measure and record zone of inhibition for four consecutive days.

\section{Results}

The result of testing mycelial culture of Ganoderma lucidum against bacteria pathogen Escherichia coli, Staphylococcus aureus, Klebsiella pneumoniae and Pseudomonas aeruginosa are presented in tables 1 and 2.

The result showed that the mycelia growth of Ganoderma lucidum was very active against all the test organisms. Table 1 shows that the zone of inhibition by mycelia of Ganoderma lucidum on the test organisms increased daily. Escherichia coli showed the highest susceptibility of $10.6 \mathrm{~mm}$ on the first day which increased to $14.9 \mathrm{~mm}$ on the fourth day and Pseudomonas aeruginosa was the least susceptible with zone of inhibition of $5.7 \mathrm{~mm}$ on the fourth day.

Table 2 shows the total inhibition of all the test organisms as the organisms were totally suppressed by the 7 day -old culture of mycelia of Ganoderma lucidum. None of the pathogenic bacteria grew when the mushroom was introduced into the media 48 hours before the pathogens were inoculated.

\section{Discussion}


This activity could be because when the polypore was inoculated into the medium $48 \mathrm{hrs}$ before the introduction of the bacteria pathogens the mycelia of the mushroom secreted some metabolites which totally suppressed the growth of the test organisms (Ofodile et al., 2005).

The results above suggest that Ganoderma lucidum contain substances that are bactericidal during its growth stages and can be used to control human bacteria pathogen which cause various diseases (Gao et al., 2002). Fang and Zhong (2002) reported the production of the antibacterial metabolite-ganoderic acid from Submerged Fermentation of Ganoderma lucidium. In the antimicrobial screening of different solvent extracts of Ganoderma lucidum on some species of bacteria reported by Ofodile and Bikomo (2008), some bioactive components such as phenolics, terpenoids and alkaloids were implicated which could also be the reason for the activity of its mycelial culture. Triterpenoid in Ganoderma lucidum has also been reported as the major antimicrobial constituents (Yihuai et al. 2003; Ofodile, 2006). The activity of the extracts from the fruiting body and mycelia of Ganoderma lucidum against some clinical bacteria in Asia have also been reported by some workers (Yoon et al., 1994; Char et al., 1997; Yihuai et al., 2003). Therefore, there are secondary metabolites released by Ganoderma lucidum which could be responsible for its antibacterial activity. Patrick et al. (1998) Ryan and Ray (2004) reported that Pseudomonas aeruginosa is notorious for resistance against synthetic antibiotics, therefore results of this work implies that the mycelia of G. lucidum can be used to combat such stubborn organism.

This antibacterial activity suggest that the mycelial culture of Ganoderma lucidum isolated from dead wood in Nigeria does indeed contain certain bioactive elements or ingredients that might be beneficial for the prevention and treatment of varieties of ailments including important diseases such as gastro-enteritis, bronchitis, respiratory tract infection, food poisoning, urinary tract infection, and lung infection.

\section{References}

Carmen W.H., \& Xi D. (2004). Chromatographic and Electrophoretic Method of lingzhi pharmacologically active components. Journal of chromatography, 812, 241-257

Chai H., Wang F., Zhang Z., \& Yang Y. (1997). Constitution from the fruiting body of Ganoderma lucidum (Fr) Karst. Zhongguo Zhongyao Zazhi Chinese Journal of Materia Medica, 22, 552-553.

Fang Q.H., \& Zhong J.J. (2002). Submerged Fermentation of Higher Fungus Ganoderma lucidium for the Production of Valuable Bio-active Metabolites-Ganoderic and Polysaccharides. Biochemical Engineering Journal, 10, 61.

Gao Y.H., Zhou S.F., Chen G.L., Ye X.H., \& Gao H. (2002). A phase 1/H Study of Ganoderma lucidium extract in patient with chronic hepatitis B. International journal of Medicinal Mushrooms, 4, 323-327.

Gao Y., Tang W., \& Dai X. (2005). Effects of water-soluble Ganoderma lucidium polysaccharides on the immune function of patients with advanced lung cancer. Journal of Medicinal Food, 8, 159-169.

Ofodile L.N. (2006). Taxonomy and Antimicrobial Activity of some Basidiomycetous Fungi in Southern Nigeria. PhD Thesis, Department of Botany and Microbiology, University of Lagos. Akoka, Lagos pp 6-44.

Ofodile L.N. \& Bikomo E.O. (2008). Antibacterial Activity of Ganoderma lucidium from Nigeria. Harmdad Medicus, 51(1), 14-17

Ofodile L.N., Kokubum N.U., Grayer O.R.J., Ogundipe O.T., \& Simmonds M.S.J. (2005). Antimicrobial Activity of Some Ganoderma Species from Nigeria. Phytotherapia Research, 19, 210-213

Patrick R., Murray K., Rosenthal S., George S.K., Micheal A.P. (1998). Medical Microbiology, Mc Grawhill New York.

Ryan K.J., \& Ray C.J. (2004). Sherris Medical Microbiology, Mc Grawhill, New York.

Smith B.J. and Sivathamparan K. (2003). Morphological Studies of Ganoderma (Ganodermataceae) from the Australiasian and Rafia Region. Australiasian Systematic Botany, 16,487-503.

Utkhede R.S, \& Rahe J.E. (1980). Biological control of onion white rot. Soil Biology and Biochemtry 12,101.

Weller D.M., Zhang B.X., \& Cook R.J. (1985). Application of rapid screening test for selection of bacteria suppression to take-all wheat. Plant Disease, 69, 710-713.

Willey I.M., Sherwood L.M., \& Woolverton C.J. (2008). Prescott, Harley and Klein's Microbiology. (7 ${ }^{\text {th }}$ Edition), McGraw-Hill, New York.

Yihuai U., Zhau S, Huang M., \& Xu A. (2003). Antibacterial and Antiviral Value of the Genus Ganoderma Species (Amphyllophoromycetideae): A Review. International Journal for Medicinal Mushrooms, 5, 235-246. 
Yoon S.Y., Kim Y.S., Lee C.K., \& Hans S.S. (1994). Antimicrobial Activity of Ganoderma lucidium extract alone and in combination with some antibiotics. Archive Pharmaceutical Research, 17, 438-442.

Zoberi M.H. (1972). Tropical Macrofungi: Some Common Species. The Macmillan Press Ltd. London.

Table 1. The mean zone of inhibition of mycelia of Ganoderma lucidum on bacteria pathogens using dual method

\begin{tabular}{|l|l|l|l|l|}
\hline TEST ORGANISMS & \multicolumn{4}{l|}{ Mean zone of inhibition (mm) per day } \\
\hline & 1 & 2 & 3 & 4 \\
\hline Escherichia coli & 10.6 & 12.5 & 13.9 & 15.2 \\
\hline Staphylococcus aureus & 10.5 & 12.6 & 13.4 & 14.9 \\
\hline Klebsiella pneumoniae & 5.7 & 5.9 & 6.5 & 6.6 \\
\hline Pseudomonas aeruginosa & 4.5 & 4.7 & 5.2 & 5.7 \\
\hline
\end{tabular}

Table 2. The mean zone of inhibition of mycelia of Ganoderma lucidum on bacteria pathogens using Weller method

\begin{tabular}{|l|l|l|l|l|}
\hline TEST ORGANISMS & \multicolumn{5}{l}{ Mean zone of inhibition (mm) per day } \\
\hline & 1 & 2 & 3 & 4 \\
\hline Escherichia coli & $\mathrm{Ti}$ & $\mathrm{Ti}$ & $\mathrm{Ti}$ & $\mathrm{Ti}$ \\
\hline Staphylococcus aureus & $\mathrm{Ti}$ & $\mathrm{Ti}$ & $\mathrm{Ti}$ & $\mathrm{Ti}$ \\
\hline Klebsiella pneumoniae & $\mathrm{Ti}$ & $\mathrm{Ti}$ & $\mathrm{Ti}$ & $\mathrm{Ti}$ \\
\hline Pseudomonas aeruginosa & $\mathrm{Ti}$ & $\mathrm{Ti}$ & $\mathrm{Ti}$ & $\mathrm{Ti}$ \\
\hline
\end{tabular}

Ti- means total inhibition 